\title{
Characterization of Botrytis cinerea Isolates from Strawberry with Reduced Sensitivity to Polyoxin D Zinc Salt
}

Madeline E. Dowling, Meng-Jun Hu, Linus T. Schmitz, Jennifer R. Wilson, and Guido Schnabel, Department of Agricultural and Environmental Sciences, Clemson University, Clemson, SC 29634

\begin{abstract}
Dowling, M. E., Hu, M.-J., Schmitz, L. T., Wilson, J. R., and Schnabel, G. 2016. Characterization of Botrytis cinerea isolates from strawberry with reduced sensitivity to polyoxin D zinc salt. Plant Dis. 100:2057-2061.

Polyoxin D is a Fungicide Resistance Action Committee (FRAC) code 19 fungicide that was recently registered for gray mold control of strawberry in the United States. In this study, we determined the sensitivity to polyoxin D zinc salt (hereafter, polyoxin D) of Botrytis cinerea isolates from 41 commercial strawberry farms in South Carolina, North Carolina, Maryland, Virginia, and Ohio and investigated the fitness of sensitive (S) and reduced sensitive (RS) isolates. Relative mycelial growth ranged between 0 and over $100 \%$ on malt extract agar amended with a discriminatory dose of polyoxin D at $5 \mu \mathrm{g} / \mathrm{ml}$. Isolates that grew more than $70 \%$ at that dose were designated RS and were found in three of the five states. The $50 \%$ effective dose $\left(\mathrm{EC}_{50}\right)$ values of three $\mathrm{S}$ and three RS isolates ranged from 0.59 to 2.27 and 4.6 to $5.8 \mu \mathrm{g} / \mathrm{ml}$, respectively.

The three RS isolates grew faster on detached tomato fruit treated with $\mathrm{Ph}-\mathrm{D}$ WDG at recommended label dosage than $\mathrm{S}$ isolates $(P<0.008)$. In all, 25 randomly selected RS isolates exhibited reduced sporulation ability $(P<0.0001)$ and growth rate $(P<0.0001)$ but increased production of sclerotia $(P<0.0386)$ compared with $25 \mathrm{~S}$ isolates. Of 10 isolates tested per phenotype, the number of RS isolates producing sporulating lesions on apple, tomato, and strawberry was significantly lower compared with $\mathrm{S}$ isolates $(P<0.0001$ for each fruit type). The results of this study indicate that resistance management is necessary for fungicides containing polyoxin D. To our knowledge, this is the first study demonstrating reduced sensitivity to FRAC 19 fungicides in B. cinerea isolates from the United States.
\end{abstract}

Botrytis cinerea, causal agent of gray mold on strawberry, was recently voted the second most scientifically and economically important fungal plant pathogen in a survey involving 495 fungal pathologists, and is arguably the most devastating disease affecting strawberry production in the world (Dean et al. 2012). It is a necrotrophic pathogen that overwinters on plant debris or weeds or in soil as sclerotia or dormant mycelium which eventually produce conidiophores and conidia in response to a favorable, moist environment (Strømeng et al. 2009; Williamson et al. 2007). Initial infection typically occurs on strawberry flowers and then spreads to the fruit (Mertely et al. 2002). The infection may remain quiescent, not appearing until fruit has matured, resulting in postharvest losses. Infection through wounds on mature or even immature fruit, leaves, or stems can also lead to severe preharvest and postharvest losses (Elad et al. 2004; Williamson et al. 2007).

In commercial settings, management of gray mold is largely dependent on chemical control (Elad et al. 2004). Multisite fungicides such as captan and thiram are commonly used in the southeastern United States in addition to single-site inhibitors that generally are more effective and less toxic (Adaskaveg et al. 2011). Multisite fungicides have low resistance risk but a high dose is required for adequate control, they lack systemic activity, and they possess little postinfection activity (Elad et al. 2004; Gauthier 2014). Resistance in $B$. cinerea to many single-site fungicides registered for gray mold control on strawberry has been documented, and isolates are emerging that are resistant to seven chemical classes (Fernández-Ortuño et al. 2015). Therefore, discovering and utilizing new modes of action for controlling gray mold is critical.

Corresponding author: G. Schnabel; E-mail: schnabe @clemson.edu

Technical Contribution Number 6430 of the Clemson University Experiment Station.

Accepted for publication 9 May 2016.

http://dx.doi.org/10.1094/PDIS-02-16-0166-RE

(C) 2016 The American Phytopathological Society
The first fungicide containing polyoxin D (Fungicide Resistance Action Committee [FRAC] code 19) was registered in 1997 for use on turf, and extension of the use of polyoxin D to several food crops, including strawberry, was made in November 2008. Since 2012, there have been two formulations available for Botrytis control on strawberry, OSO 5\%SC (Certis, Columbia, MD) and Ph-D WDG (Arysta LifeScience North America, LLC, Cary, NC). Polyoxin D prevents chitin formation in the cell wall by competitively inhibiting the chitin synthetase enzyme (Endo et al. 1970). This inhibits mycelial growth and spore germination, often weakening the cell walls of hyphae or germ tubes until they rupture (Adaskaveg et al. 2011; BartnickiGarcia and Lippman 1972; Becker et al. 1983). This mode of action is nontoxic to mammals and plants, because they lack chitin (Environmental Protection Agency 2008). On strawberry, field reentry interval and preharvest intervals are low at 0 and $4 \mathrm{~h}$, respectively, making it an attractive product for U-pick operations (Brannen et al. 2016).

As part of a project to provide location-specific resistance management information to eastern U.S. strawberry growers, we determined the sensitivity to polyoxin D zinc salt (hereafter, polyoxin D) for $B$. cinerea isolates. None of the participating growers had begun using this chemistry in their fields in 2015 . The goals for this study were to (i) determine mycelial growth inhibition of isolates from the east coast at a discriminatory dose of $5 \mu \mathrm{g} / \mathrm{ml}$, (ii) examine the sensitivity of isolates on both sides of the sensitivity spectrum to the recommended label dosage of Ph-D WDG, and (iii) determine fitness and pathogenicity of isolates with reduced sensitivity. This study is the first to document reduced sensitivity to polyoxin $\mathrm{D}$ in $B$. cinerea isolates collected from strawberry fields in the United States.

\section{Materials and Methods}

Isolate collection and determination of sensitivity to polyoxin $\mathrm{D}$. Between April and June 2015, strawberry blossoms and leaves were collected from 41 commercial farms in 33 counties in South Carolina, North Carolina, Maryland, Virginia, and Ohio. Fungicide use histories provided by growers indicated no prior applications of fungicides containing polyoxin D. Each flower sample had a black torus indicative of frost damage. Petals and sepals were removed and flowers and leaves were surface disinfested, rinsed, and incubated as described previously (Fernández-Ortuño et al. 2014). Conidia forming 
on incubated tissue were transferred with a sterile toothpick into 90-mm-diameter petri dishes containing approximately $15 \mathrm{ml}$ of malt extract agar (Difco MEA; Fisher Scientific, Hampton, NH). Though single-spore isolation was not performed, only a few conidia were removed on the tip of the toothpick, and sequencing of 30 isolates revealed no conflicting signals due to the potential presence of multiple genotypes. In total, $459 \mathrm{~B}$. cinerea isolates were obtained from South Carolina $(n=211)$, North Carolina $(n=101)$, Maryland $(n=123)$, Virginia $(n=17)$, and Ohio $(n=7)$ and subjected to sensitivity tests. A subset of randomly picked sensitive (S), moderately sensitive (MS), and reduced sensitive (RS) isolates was used for fitness and pathogenicity testing.

Relative growth of isolates was determined on MEA amended with polyoxin D at $5 \mu \mathrm{g} / \mathrm{ml}$ (PH-D fungicide; Arysta LifeScience North America, LLC). The discriminatory dose of polyoxin D at $5 \mu \mathrm{g} / \mathrm{ml}$ was about three times higher than published $50 \%$ effective dose $\left(\mathrm{EC}_{50}\right)$ values for sensitive $B$. cinerea isolates from sweet basil (Mamiev et al. 2013). Preliminary tests verified that mycelial growth of 10 randomly picked isolates in our collection was completely inhibited at that dose (data not shown). Calculating a dose to discriminate $\mathrm{S}$ from truly resistant isolates that are not controlled by label rates in the field was not possible because we have not observed such isolates yet. Mycelial plugs from margins of actively growing colonies on MEA were used to inoculate three plates for each isolate. After 2 days, two measurements of each colony diameter were taken, and the mean relative growth of each isolate was calculated. Isolates that did not grow on treated plates were designated $\mathrm{S}$; isolates that grew $70 \%$ or less of the control were designated MS; and isolates that grew more than $70 \%$ of the control were designated RS. We chose the $70 \%$ growth rate threshold to distinguish MS from RS isolates because there appeared to be a normal distribution of isolates that are not sensitive to $\mathrm{Ph}-\mathrm{D}$, and $70 \%$ was just past the peak of this curve. $\mathrm{EC}_{50}$ values were determined for three $\mathrm{S}$ and three $\mathrm{RS}$ isolates using a spore germination test (Kretschmer et al. 2009). Final conidia concentrations of $1.5 \times 10^{4}$ conidia/ml of malt extract broth (Amresco, Solon, $\mathrm{OH}$ ) and polyoxin D at $100,30,10,3,1,0.3$, and $0.1 \mu \mathrm{g} / \mathrm{ml}$ of water were used. Gen5 (Biotek Instruments, Winooski, VT) software was used to calculate $\mathrm{EC}_{50}$ values.

Management of gray mold on detached fruit treated with polyoxin D. A detached fruit study was performed to determine whether the dose of polyoxin D recommended for field control of gray mold would control both S and RS isolates under controlled conditions. Three $\mathrm{S}$ and three $\mathrm{RS}$ isolates from different locations (Table 1) were treated with water (control), polyoxin D (PH-D WDG; Arysta LifeScience North America, LLC), or fludioxonil (Switch 62.5WG; Syngenta Crop Protection, Greensboro, NC). Commercially grown cherry tomato fruit were washed with an alconox detergent solution, rinsed with sterile water for $10 \mathrm{~s}$, and air dried in a laminar flow hood. After drying, fruit were stabbed once halfway between the top and bottom of the fruit to a depth of approximately $1 \mathrm{~cm}$ with a 1-mm-diameter sterilized inoculation needle and placed on plastic rings ( $3.5 \mathrm{~cm}$ in diameter) with the injured side facing up in plastic boxes with sealable lids ( 23.5 by 23.5 by $9.0 \mathrm{~cm}$ ). A moist paper towel was placed underneath the plastic rings in the bottom of each box to increase humidity. Nine tomato fruit were placed in a box and inoculated as described below with the same isolate, and each treatment was applied to three of these fruit. Each box was replicated three times, and treatment and isolate locations were

Table 1. Values of $50 \%$ effective dose $\left(\mathrm{EC}_{50}\right)$ of isolates used to determine sensitivity on tomato to recommended field dosage of Ph-D WDG fungicide

\begin{tabular}{lccl}
\hline Isolate & Phenotype $^{\mathbf{z}}$ & EC $_{\mathbf{5 0}}$ value & \multicolumn{1}{c}{ Origin } \\
\hline $34-4-15$ & $\mathrm{RS}$ & 5.8 & Mullins, SC \\
Z20M & $\mathrm{RS}$ & 5.2 & York, SC \\
Z32L & $\mathrm{RS}$ & 4.6 & York, SC \\
$13-8-15$ & $\mathrm{~S}$ & 0.59 & Pelion, SC \\
$28-9-15$ & $\mathrm{~S}$ & 1.87 & Huntingtown, MD \\
$10-1-15$ & $\mathrm{~S}$ & 2.72 & Monetta, SC \\
\hline
\end{tabular}

${ }^{\mathrm{z}} \mathrm{RS}=$ with reduced sensitivity and $\mathrm{S}=$ sensitive to the fungicide. randomized. Prior to inoculation, spore suspensions (final concentration of $10^{5}$ spores $/ \mathrm{ml}$ ) were mixed with individual fungicides at final concentrations of PH-D WDG at $0.93 \mathrm{~g} /$ liter (water at 467.8 liters/ha) and Switch $62.5 \mathrm{WG}$ at $1.9 \mathrm{~g} / \mathrm{liter}$ ( $\mathrm{Li}$ et al. 2014). A $20-\mu$ l droplet of the conidia + fungicide was pipetted onto each stab injury. Boxes were sealed and kept at $19^{\circ} \mathrm{C}$ and 98 to $100 \%$ relative humidity $(\mathrm{RH})$ for the first $24 \mathrm{~h}$. Then, the lid was opened but not removed, and the microclimate adjusted to lab conditions $\left(19^{\circ} \mathrm{C}\right.$ and $\left.60 \% \mathrm{RH}\right)$. After 5 days, growth was assessed and mean relative growth was calculated. The experiment was repeated once.

In vitro fitness comparison. Fitness parameters of 25 randomly selected $\mathrm{S}$ and 25 randomly selected RS isolates were investigated on potato dextrose agar (PDA) and minimal media (MM). Mycelial plugs ( $3.5 \mathrm{~mm}$ in diameter) were transferred from the margin of actively growing cultures to fresh PDA and MM plates, with three replications for each isolate and each medium. Colony diameters were measured after $24 \mathrm{~h}$ of incubation under fluorescent light at $22^{\circ} \mathrm{C}$. The cultures were incubated for 12 more days under the same conditions. Colonies were examined for conidia production and MM plates were also assessed for production of sclerotia. All conidia were scraped off and rinsed from culture plates with a sterile inoculating loop and $10 \mathrm{ml}$ of distilled sterile water, respectively. Spore suspensions were vortexed, then diluted, and the number of spores per plate was determined using a hemacytometer.

In vivo pathogenicity and fitness comparison. Fitness parameters between $\mathrm{S}$ and RS isolates were determined on detached apple, strawberry, and tomato fruit. Fruit were purchased from the grocery store, washed with alconox detergent for $10 \mathrm{~s}$, dipped in $10 \%$ bleach solution for $1 \mathrm{~m}$, rinsed with water, and placed in a laminar flow hood to dry for 2 to $4 \mathrm{~h}$. Inoculations were performed with 10 randomly selected $\mathrm{S}$ and 10 randomly selected RS isolates by removing a 3.5-mm-diameter plug from each fruit with a cork borer and replacing it with a mycelial plug of the same size. Three apple quarters, three strawberry fruit, and nine tomato fruit were inoculated with each isolate. Measurements from three tomato fruit were averaged and considered a single unit because of the greater variability in measuring lesions on such a small and curved surface. Each fruit unit was inoculated with a single plug placed at the widest part of each fruit. Isolates were randomly distributed into sealable plastic boxes until each box contained 5 strawberry fruit, 5 apple quarters, or 15 tomato fruit. Boxes containing apple and strawberry were the same as those described above for the in vivo detached-fruit assay, and fruit were placed on rings and moist paper towels as described above. Boxes used for the tomato fruit were larger ( 34.0 by 23.5 by $7.5 \mathrm{~cm}$ ) to allow for more replicates per box. There were three replicates of each box, and box position and isolate location within each box was randomized. The RH was maintained at 98 to $100 \%$ for the first $24 \mathrm{~h}$; then, the lid was opened but not removed. Growth rates were measured after $48 \mathrm{~h}$ by determining the lesion diameter on each fruit. After 6 days of inoculation, fruit were examined for conidia production. The entire experiment was replicated once.

Data analysis. A statistical model was developed to determine the experimental factor in various response tests (growth rate, sporulation, number of spores, number of sclerotia, production of sclerotia, and so on). For replications exhibiting experimental effects, an analysis of variance was performed to determine whether the experiments could be combined. To detect significant differences in continuous data (growth rate, spore concentration, and number of sclerotia), a Student's $t$ test was performed. To detect significant differences in binary data (presence or absence of spores or presence or absence of sclerotia), Fischer's Exact Test and $\chi^{2}$ tests were used. All statistical testing was performed using the software JMP 11.0 (SAS Institute, Inc., Cary, NC) and with a significance level of $\alpha=0.05$.

\section{Results}

Sensitivity to polyoxin D in vitro. Out of the 459 isolates tested for sensitivity to polyoxin D, $351(76.5 \%)$ were $S$ and unable to grow, $29(6.3 \%)$ were RS and grew at a rate of $>70 \%$, while $79(17.2 \%)$ were MS and grew at a rate of $70 \%$ or less on media amended with 
polyoxin D at $5 \mu \mathrm{g} / \mathrm{ml}$ (Fig. 1). Interestingly, most RS isolates were found in South Carolina but some were found in North Carolina and Maryland. MS isolates were found in all five states (Fig. 2). The $\mathrm{EC}_{50}$ values of three randomly chosen $\mathrm{S}$ isolates (10-1-15, 13-8-15, and 28-9-15) ranged from 0.59 to $2.72 \mu \mathrm{g} / \mathrm{ml}$, while the $\mathrm{EC}_{50}$ values for three randomly selected RS isolates (34-4-15, Z32 L, and Z20M) ranged from 4.6 to $5.8 \mu \mathrm{g} / \mathrm{ml}$ (Table 1).

Relative growth of $\mathrm{S}$ and $\mathrm{RS}$ isolates on tomato following inoculation with and without polyoxin $D$. Growth rates of $S$ isolates 10-1-15, 13-8-15, and 28-9-15 and RS isolates 34-4-15, Z32 L, and Z20M (Table 1) were compared on detached tomato fruit while exposed to a field dose of polyoxin D. No significant difference was observed between the two independent experiments $(P>0.057)$ and, therefore, the data were combined. Relative growth of RS isolates was significantly faster on tomato in the presence of polyoxin D compared with $\mathrm{S}$ isolates $(P<0.008$; Fig. 3$)$. The untreated controls typically grew fluffy white masses of mycelium and developed conidia, though sporulation was rare for RS isolates. Both RS and S isolates produced very thin, spidery mycelium on fruit when inoculated in the presence of polyoxin $\mathrm{D}$. None of the isolates grew on tomato fruit when exposed to Switch 62.5WG fungicides during inoculation.

In vitro fitness comparison. Growth rate, number of sporulating isolates, spore concentration, number of isolates producing sclerotia, and number of sclerotia was determined for $25 \mathrm{~S}$ isolates and $25 \mathrm{RS}$ isolates on MM and PDA. More RS isolates produced sclerotia compared with $\mathrm{S}$ isolates $(P<0.0386)$ but no differences was found in number of sclerotia per plate. RS isolates grew significantly slower on PDA $(P<0.0001)$ and MM $(P<0.0001)$ and were less likely to sporulate on PDA $(P<0.0001)$ and MM $(P<0.0001)$ compared with $\mathrm{S}$ isolates. There were no significant differences between $\mathrm{RS}$ and $\mathrm{S}$ isolates for spore concentration $(P>0.35$ on PDA, $P>0.86$ on $\mathrm{MM})$ and number of sclerotia produced $(P>0.072$ on $\mathrm{MM})$. On both types of media, most RS isolates produced sparse to fluffy white mycelium, whereas $\mathrm{S}$ isolates generally produced typical greyish white mycelium and conidia. Sclerotia produced by RS isolates on $\mathrm{MM}$ often formed concentric rings, while sclerotia of S isolates were scattered and rarely formed a pattern (Table 2).

Evaluation of fitness parameters on apple, tomato, and strawberry fruit. Fitness parameters of $10 \mathrm{~S}$ isolates and $10 \mathrm{RS}$ isolates were investigated on apple, tomato, and strawberry. Experimental effects were observed between the two independent growth rate experiments for strawberry $(P<0.0001)$ and tomato $(P<0.0001)$; therefore, data were not combined. All isolates were able to produce lesions on the three fruit. Growth rates differed significantly between $\mathrm{S}$ and RS isolates on tomato in both experiments and on apple and strawberry in the second experiments $(P<0.0001$ on apple, $P<0.0001$ on strawberry). The

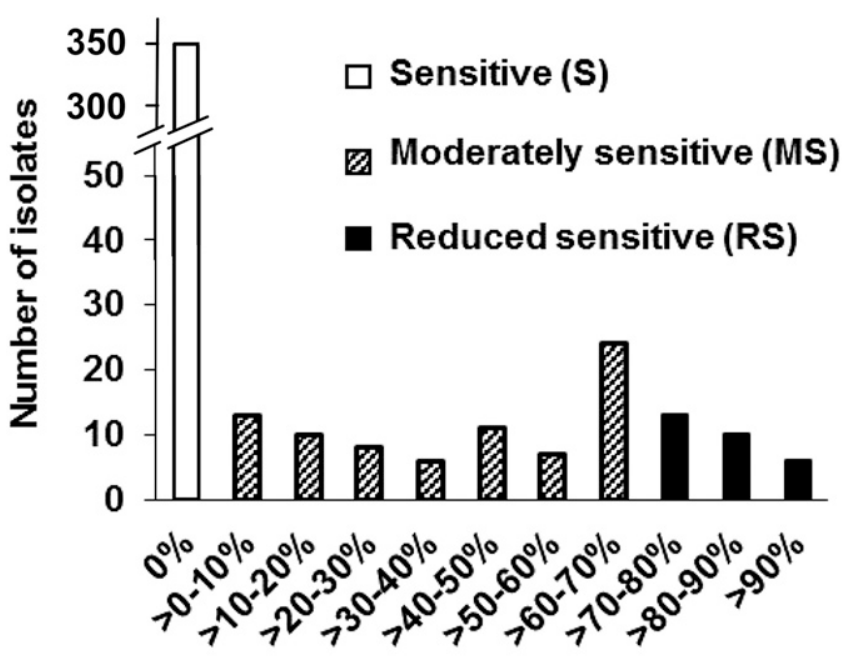

\section{Relative growth on $5 \mu \mathrm{g} / \mathrm{ml}$ polyoxin D}

Fig. 1. Relative growth of 459 Botrytis cinerea isolates from five states on potato dextrose agar amended with polyoxin $D$ at $5 \mu \mathrm{g} / \mathrm{ml}$. number of sporulating lesions was consistent for all fruit types, with $\mathrm{S}$ isolates sporulating significantly more than RS isolates for apple $(P<0.0001)$, tomato $(P<0.0001)$, and strawberry $(P<0.0001)$ (Table 3).

\section{Discussion}

In this study, we investigated sensitivity to polyoxin D in 459 $B$. cinerea isolates from five states in the eastern United States and found a wide range of sensitivity. Though most of the isolates collected were $\mathrm{S}, 17.2 \%$ were MS and $6.3 \%$ were RS to polyoxin $\mathrm{D}$, despite the absence of pressure from FRAC 19 fungicides. The $\mathrm{RS}$ isolates were able to outgrow $\mathrm{S}$ isolates on tomato fruit treated with a dose of Ph-D WDG recommended for field applications. S isolates were completely inhibited when subjected to Switch but they were only slowed down when exposed to Ph-D WDG. This was expected because Switch is a standard for Botrytis spp. control and polyoxin $\mathrm{D}$ was not expected to perform as well, though it still provides a certain level of protection in the field (G. Schnabel, personal communication). Also, tomato fruit were stabbed prior to inoculation, providing extremely favorable conditions for infection. The effect, although statistically significant, was small and, therefore, it is possible that field applications of Ph-D WDG at the recommended label rate control $\mathrm{S}$ and RS isolates equally well. However, the reduced sensitivity was associated with a fitness cost, because RS isolates typically had slower growth rates and were less likely to sporulate than $\mathrm{S}$ isolates. However, RS isolates were able to produce more sclerotia than $\mathrm{S}$ isolates in our experimental setup. If this ability is confirmed in the field, such isolates may have a survival advantage over $\mathrm{S}$ isolates in the absence of polyoxin $\mathrm{D}$ fungicide selection pressure.

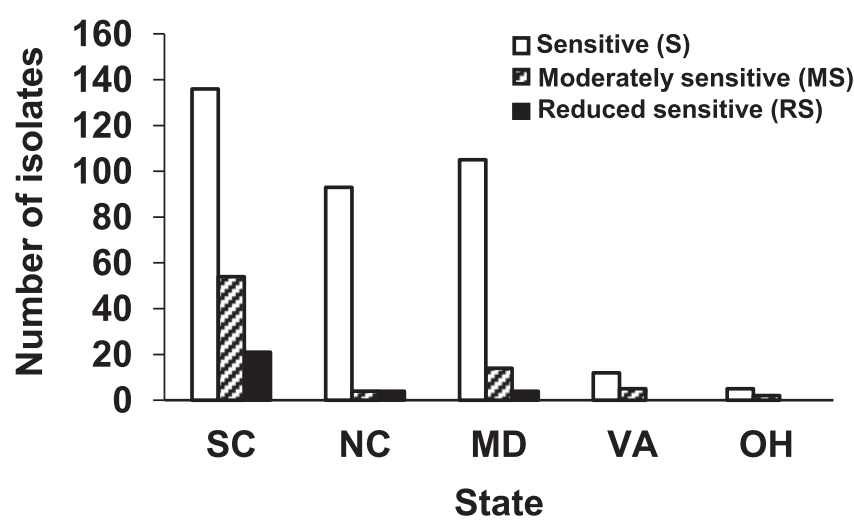

Fig. 2. Distribution of Botrytis cinerea isolates sensitive (S), moderately sensitive (MS), and with reduced sensitivity (RS) to polyoxin D in South Carolina (SC), North Carolina $(\mathrm{NC})$, Maryland (MD), Virginia (VA), and Ohio (OH).

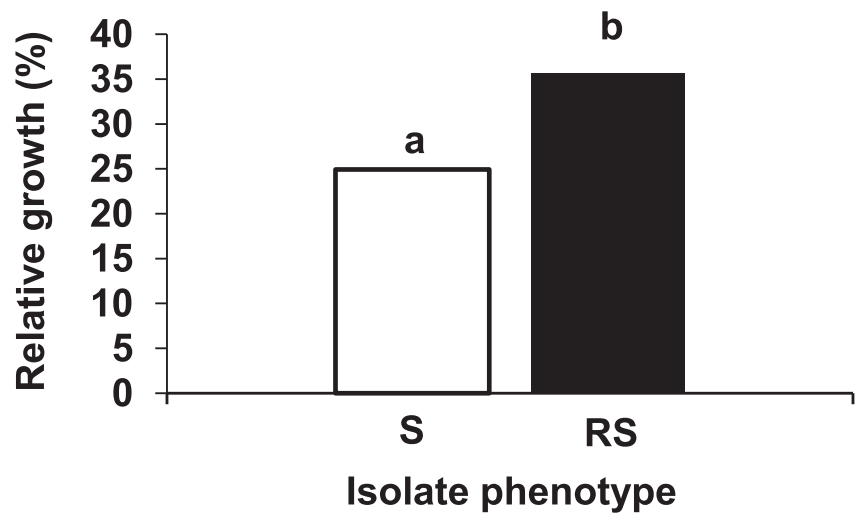

Fig. 3. Average relative growth of sensitive (S) and reduced sensitive (RS) isolates on detached tomato fruit at a field dosage of Ph-D WDG fungicide. 
Reduced sensitivity to FRAC 19 fungicides in the absence of prior polyoxin selection pressure was previously found in $B$. cinerea isolates from sweet basil grown in greenhouses in Israel. In that study, similar parameters were evaluated, including relative growth analysis on a discriminatory dose of fungicide, growth rate on unamended media, and $\mathrm{EC}_{50}$ analysis. The main differences between their methods and ours were that they used a modified version of Czapek-Dox media, a discriminatory dose of $1 \mu \mathrm{g} / \mathrm{ml}$ for relative growth analysis, and polyoxin A-L fungicide instead of polyoxin D. Polyoxin A- $\mathrm{L}$ is a mixture of polyoxins that includes polyoxin D. However, results between that study and our study were fairly consistent, with 20 to $35 \%$ of the isolates collected prior to polyoxin A-L application showing low-level resistance to polyoxin D. These consistently high numbers of isolates with reduced sensitivity prior to fungicide application were surprising because the number of RS isolates present in a field prior to fungicide application are usually relatively low compared with the number of $\mathrm{S}$ isolates. $\mathrm{EC}_{50}$ values of low-level resistant isolates collected by Mamiev et al. (2013) ranged between 4 and $6.5 \mu \mathrm{g} / \mathrm{ml}$, consistent with the range of 4.6 to $5.8 \mu \mathrm{g} / \mathrm{ml}$ obtained for our RS isolates. However, in contrast to our study, the authors found no fitness penalties in the low-level resistant isolates, though they only examined growth rate in vitro and not sporulation or production of sclerotia (Mamiev et al. 2013).

There may be several explanations for the observed preexistence of reduced sensitivity to polyoxin D in $B$. cinerea isolates. $B$. cinerea populations have been shown to have inherently broad genetic diversity. In a study of $B$. cinerea isolates from South Carolina, genetic differences were detected between all 56 isolates collected, though multiple isolates were collected from each sampled greenhouse (Yourman et al. 2001). Single plants and even lesions were found to contain five or more different haplotypes in a European study (Giraud et al. 1997). The cause of this high diversity is not known but has been attributed to multiple phenomena, including sexual recombination, transposon movement, and heterokaryosis. Because of B. cinerea's high diversity, certain specialized isolates may be inherently resistant to a fungicide before it is applied. One European study discovered two genetically distinct groups within $B$. cinerea: one with inherent tolerance to fenhexamid and the other sensitive to fenhexamid (Fournier et al. 2005; Kretschmer and Hahn 2008). Therefore, the broad diversity of $B$. cinerea may result in the coexistence of isolates with sensitivity and inherent reduced sensitivity to polyoxin D.

Another possible explanation for the presence of reduced sensitivity is that exposure to other chemical classes of fungicides predisposed them to reduced sensitivity to polyoxin D. In Venturia inequalis isolates, cross-resistance between methyl benzimidazole carbamate (MBC) fungicides and demethylation inhibitors (DMI) fungicides was detected. The authors proposed that this cross-resistance could be due to fungicide selection for greater genome plasticity, potentially by affecting DNA repair systems. This predisposition to resistance across chemical classes could result in reduced sensitivity to fungicides before their widespread use (Köller and Wilcox 2001).

The reduced sensitivity we observed also may be related to multidrug resistance (MDR), which stems from upregulation of drug efflux pumps in the cell membrane. Based on conventional definitions of resistance, RS isolates appear to have quantitative resistance because there are varying levels of sensitivity to polyoxin D (Delp 1988). Though multiple mutations conferring increasing levels of resistance are one possible cause of this reduced sensitivity, another possibility is that overexpression of genes such as those involved in drug efflux may cause the RS phenotype. Though the resistance mechanism to polyoxin $\mathrm{D}$ is currently unknown, upregulation of $\mathrm{ABC}$ transporters after exposure to polyoxins has been documented as well as increased sensitivity to polyoxins when the $\mathrm{ABC}$ transporter gene $B M R l$ was knocked out (Makizumi et al. 2002; Nakajima et al. 2001). Some work indicates that MDR isolates do not typically have fitness costs associated with them as our isolates did (Kretschmer et al. 2009). However, other recent work (Chen et al. in press) indicates that, though production of sclerotia, sclerotia viability, sporulation, growth rate, and oxidative sensitivity were no different between $S$ and MDR1h isolates, osmotic sensitivity is greater and growth rate in colder temperatures is slower in MDR1h isolates.

Polyoxin D has a unique mode of action that has not yet been used on strawberry, which makes it an attractive candidate for tank mixing and rotation with other single-site inhibitor fungicides. However, the results of this study demonstrate that isolates with reduced sensitivity to polyoxin D are already present in many locations of the eastern United States. It is unknown whether RS isolates can be controlled effectively by field rates of formulated products containing polyoxin D. Low-level resistant isolates from sweet basil in Israel never developed into highly resistant isolates over a 10 -year period, though lowlevel resistance increased in frequency from 20 to $73 \%$ in response to polyoxin A-L application (Mamiev et al. 2013). As outlined in this study, FRAC 19 fungicides such as polyoxin D are vulnerable to resistance development and, therefore, should be integrated into resistance management programs to delay further selection of RS isolates.

\section{Acknowledgments}

This material is based upon work supported by the United States Department of Agriculture National Institute of Food and Agriculture (USDA-NIFA) under

Table 2. In vitro fitness components for Botrytis cinerea isolates sensitive (S) and with reduced sensitivity (RS) to polyoxin D evaluated on potato dextrose agar (PDA) and minimal media $(\mathrm{MM})^{\mathrm{w}}$

\begin{tabular}{|c|c|c|c|c|c|c|c|c|}
\hline \multirow[b]{2}{*}{ Phenotype } & \multicolumn{2}{|c|}{ Growth rate } & \multicolumn{2}{|c|}{ Sporulating (\%) } & \multicolumn{2}{|c|}{ Spores/plate ${ }^{x}$} & \multirow{2}{*}{$\frac{\text { Sclerotia }(\%)^{y}}{M M}$} & \multirow{2}{*}{$\frac{\text { Sclerotia }(n)^{\mathbf{z}}}{\mathrm{MM}}$} \\
\hline & PDA & MM & PDA & $\mathbf{M M}$ & PDA & MM & & \\
\hline $\bar{S}$ & $2.16 \mathrm{a}$ & $2.10 \mathrm{a}$ & $88 \mathrm{a}$ & $96 \mathrm{a}$ & $6.64 \mathrm{a}$ & $6.34 \mathrm{a}$ & $25 \mathrm{a}$ & $16.78 \mathrm{a}$ \\
\hline RS & $1.99 \mathrm{~b}$ & $1.80 \mathrm{~b}$ & $16 \mathrm{~b}$ & $8 \mathrm{~b}$ & $6.5 \mathrm{a}$ & $6.30 \mathrm{a}$ & $48 \mathrm{~b}$ & $17.4 \mathrm{a}$ \\
\hline
\end{tabular}

${ }^{w}$ Numbers followed by the same letter within columns were not significantly different at $\alpha=0.05$.

$x$ Only sporulating isolates were included in the analysis.

y Isolates (\%) producing sclerotia.

${ }^{\mathrm{z}}$ Only isolates producing sclerotia were included in the analysis.

Table 3. Fitness of Botrytis cinerea isolates sensitive (S) and with reduced sensitivity (RS) to polyoxin D on apple, tomato, and strawberry fruit ${ }^{2}$

\begin{tabular}{lcccccrr}
\hline & & \multicolumn{3}{c}{ Growth rate $(\mathbf{c m} / \mathbf{d a y})$} & & \multicolumn{2}{c}{ Sporulating lesions (\%) } \\
\cline { 3 - 7 } Experiment & Phenotype & Apple & Tomato & Strawberry & Apple & Tomato & Strawberry \\
\hline 1 & S & $0.61 \mathrm{a}$ & $0.66 \mathrm{a}$ & $0.53 \mathrm{a}$ & $33.3 \mathrm{a}$ & $88.89 \mathrm{a}$ & $100.00 \mathrm{a}$ \\
& RS & $0.61 \mathrm{a}$ & $0.55 \mathrm{~b}$ & $0.47 \mathrm{a}$ & $6.67 \mathrm{~b}$ & $4.00 \mathrm{~b}$ & $59.00 \mathrm{~b}$ \\
2 & S & $0.68 \mathrm{a}$ & $0.76 \mathrm{a}$ & $0.65 \mathrm{a}$ & $46.67 \mathrm{a}$ & $91.11 \mathrm{a}$ & $100.00 \mathrm{a}$ \\
& RS & $0.59 \mathrm{~b}$ & $0.67 \mathrm{~b}$ & $0.51 \mathrm{~b}$ & $10.00 \mathrm{~b}$ & $32.22 \mathrm{~b}$ & $56.00 \mathrm{~b}$ \\
\hline
\end{tabular}

\footnotetext{
${ }^{\mathrm{z}}$ Values followed by the same letter within columns of each experiment indicate no statistical difference $(\alpha=0.05)$.
} 
project number SC-1700501 and USDA-NIFA Specialty Crops Research Initiative grant number 2014-51181-22377.

\section{Literature Cited}

Adaskaveg, J. E., Gubler, W., Michailides, T. J., and Holtz, B. A. 2011. Efficacy and Timing of Fungicides, Bactericides, and Biologicals for Deciduous Tree Fruit, Nut, Strawberry, and Vine Crops 2011. Department of Plant Pathology, University of California, Davis.

Bartnicki-Garcia, S., and Lippman, E. 1972. Inhibition of Mucor rouxii by polyoxin D: Effects on chitin synthetase and morphological development. J. Gen. Microbiol. 71:301-309.

Becker, J. M., Covert, N. L., Shenbagamurthi, P., Steinfeld, A. S., and Naider, F. 1983. Polyoxin D inhibits growth of zoopathogenic fungi. Antimicrob. Agents Chemother. 23:926-929.

Brannen, P., Smith, P., Louws, F., Hicks, C., Johnson, C., Schnabel, G., Fontenot, K., Burrack, H., Jennings, K., and Mitchem, W. 2016. 2016 Southeast Regional Strawberry Integrated Pest Management Guide. Available online: www. smallfruits.org

Chen, S. N., Luo, C. X., Hu, M. J., and Schnabel, G. Fitness and competitive ability of Botrytis cinerea isolates with resistance to multiple chemical classes of fungicides. Phytopathology. In press. doi:10.1094/PHYTO-0216-0061-R

Dean, R., Van Kan, J. A., Pretorius, Z. A., Hammond-Kosack, K. E., Di Pietro, A., Spanu, P. D., Rudd, J. J., Dickman, M., Kahmann, R., and Ellis, J. 2012. The top 10 fungal pathogens in molecular plant pathology. Mol. Plant Pathol. 13:414-430.

Delp, C. J. 1988. Fungicide Resistance in North America. American Phytopathological Society, St. Paul, MN.

Elad, Y., Williamson, B., Tudzynski, P., and Delen, N. 2004. Botrytis: Biology, Pathology and Control. Springer, Dordrecht, The Netherlands.

Endo, A., Kakiki, K., and Misato, T. 1970. Mechanism of action of the antifungal agent polyoxin D. J. Bacteriol. 104:189-196.

Environmental Protection Agency. 2008. Polyoxin D Zinc Salt; Amendment to an Exemption from the Requirement of a Tolerance. Federal Register 2012-22315.

Fernández-Ortuño, D., Grabke, A., Bryson, P. K., Amiri, A., Peres, N. A., and Schnabel, G. 2014. Fungicide resistance profiles in Botrytis cinerea from strawberry fields of seven southern US states. Plant Dis. 98:825-833.

Fernández-Ortuño, D., Grabke, A., Li, X., and Schnabel, G. 2015. Independent Emergence of Resistance to Seven Chemical Classes of Fungicides in Botrytis cinerea. Phytopathology 105:424-432.

Fournier, E., Giraud, T., Albertini, C., and Brygoo, Y. 2005. Partition of the Botrytis cinerea complex in France using multiple gene genealogies. Mycologia 97:1251-1267
Gauthier, N. W. 2014. Effectiveness of Fungicides for Management of Strawberry Diseases. Cooperative Extension Service University of Kentucky College of Agriculture, Food and Environment PPFS-FR-S-15.

Giraud, T., Fortini, D., Levis, C., Leroux, P., and Brygoo, Y. 1997. RFLP markers show genetic recombination in Botryotinia fuckeliana (Botrytis cinerea) and transposable elements reveal two sympatric species. Mol. Biol. Evol. 14: $1177-1185$

Köller, W., and Wilcox, W. F. 2001. Evidence for the predisposition of fungicideresistant isolates of Venturia inaequalis to a preferential selection for resistance to other fungicides. Phytopathology 91:776-781.

Kretschmer, M., and Hahn, M. 2008. Fungicide resistance and genetic diversity of Botrytis cinerea isolates from a vineyard in Germany. J. Plant Dis. Prot. 115 214-219.

Kretschmer, M., Leroch, M., Mosbach, A., Walker, A., Fillinger, S., Mernke, D. Schoonbeek, H., Pradier, J., Leroux, P., and De Waard, M. A. 2009. Fungicide-driven evolution and molecular basis of multidrug resistance in field populations of the grey mould fungus Botrytis cinerea. PLoS Pathog. 5:e1000696

Li, X., Fernández-Ortuño, D., Grabke, A., and Schnabel, G. 2014. Resistance to fludioxonil in Botrytis cinerea isolates from blackberry and strawberry. Phytopathology 104:724-732.

Makizumi, Y., Takeda, S., Matsuzaki, Y., Nakaune, R., Hamamoto, H., Akutsu, K. and Hibi, T. 2002. Cloning and selective toxicant-induced expression of BMR1 and BMR3, novel ABC transporter genes in Botrytis cinerea. J. Gen. Plant Pathol. 68:338-341.

Mamiev, M., Korolev, N., and Elad, Y. 2013. Resistance to polyoxin AL and other fungicides in Botrytis cinerea collected from sweet basil crops in Israel. Eur. J. Plant Pathol. 137:79-91.

Mertely, J., MacKenzie, S., and Legard, D. 2002. Timing of fungicide applications for Botrytis cinerea based on development stage of strawberry flowers and fruit. Plant Dis. 86:1019-1024.

Nakajima, M., Suzuki, J., Hosaka, T., Tadaaki, H., and Akutsu, K. 2001 Functional analysis of an ATP-binding cassette transporter gene in Botrytis cinerea by gene disruption. J. Gen. Plant Pathol. 67:212-214.

Strømeng, G. M., Hjeljord, L. G., and Stensvand, A. 2009. Relative contribution of various sources of Botrytis cinerea inoculum in strawberry fields in Norway. Plant Dis. 93:1305-1310.

Williamson, B., Tudzynski, B., Tudzynski, P., and van Kan, J. A. 2007. Botrytis cinerea: The cause of grey mould disease. Mol. Plant Pathol. 8 561-580.

Yourman, L., Jeffers, S., and Dean, R. 2001. Phenotype instability in Botrytis cinerea in the absence of benzimidazole and dicarboximide fungicides. Phytopathology 91:307-315. 